\title{
Repetitive Transcranial Magnetic Stimulation
}

National Cancer Institute

\section{Source}

National Cancer Institute. Repetitive Transcranial Magnetic Stimulation. NCI Thesaurus. Code C154664.

A form of brain stimulation therapy that has been studied as a treatment for depression, psychosis, anxiety, and other disorders. 